San Jose State University

SJSU ScholarWorks

Master's Theses

Master's Theses and Graduate Research

Fall 2018

\title{
Different Methods of Embodied Cognition in Pedagogy and its Effectiveness in Student Learning
}

Cassandra Durkee

San Jose State University

Follow this and additional works at: https://scholarworks.sjsu.edu/etd_theses

\section{Recommended Citation}

Durkee, Cassandra, "Different Methods of Embodied Cognition in Pedagogy and its Effectiveness in Student Learning" (2018). Master's Theses. 4963.

DOI: https://doi.org/10.31979/etd.365e-8v4t

https://scholarworks.sjsu.edu/etd_theses/4963

This Thesis is brought to you for free and open access by the Master's Theses and Graduate Research at SJSU ScholarWorks. It has been accepted for inclusion in Master's Theses by an authorized administrator of SJSU ScholarWorks. For more information, please contact scholarworks@sjsu.edu. 


\title{
DIFFERENT METHODS OF EMBODIED COGNITION IN PEDAGOGY AND ITS EFFECTIVENESS IN STUDENT LEARNING
}

\author{
A Thesis \\ Presented to \\ The Faculty of the Department of Psychology \\ San José State University \\ In Partial Fulfillment \\ of the Requirements for the Degree \\ Master of Arts \\ by \\ Cassandra Durkee
}

December 2018 
(C) 2018

Cassandra Durkee

ALL RIGHTS RESERVED 
The Designated Thesis Committee Approves the Thesis Titled

DIFFERENT METHODS OF EMBODIED COGNITION IN PEDAGOGY AND ITS EFFECTIVENESS IN STUDENT LEARNING

by

Cassandra Durkee

APPROVED FOR THE DEPARTMENT OF PSYCHOLOGY

SAN JOSÉ STATE UNIVERSITY

December 2018

Robert Cooper, Ph.D.

Department of Psychology

Ronald Rogers, Ph.D.

Department of Psychology

Gregory Feist, Ph.D.

Department of Psychology 


\section{ABSTRACT \\ DIFFERENT METHODS OF EMBODIED COGNITION IN PEDAGOGY AND ITS EFFECTIVENESS IN STUDENT LEARNING \\ by Cassandra Durkee}

The Mathematical Idea Analysis hypothesizes that abstract mathematical reasoning is unconsciously organized and integrated with sensory-motor experience. Basic research testing movement, language, and perception during math problem solving supports this hypothesis. Applied research primarily measures students' performance on math tests after they engage in analogous sensory-motor tasks, but findings show mixed results. Sensory-motor tasks are dependent on several moderators (e.g., instructional guidance, developmental stage) known to help students learn, and studies vary in how each moderator is implemented. There is little research on the effectiveness of sensorymotor tasks without these moderators. This study compares different approaches to working with an interactive application designed to emulate how people intrinsically solve algebraic equations. A total of 130 participants ( 84 females, 54 males) were drawn from a pool of Introductory Psychology students attending San Jose State University. Participants were placed in three different learning environments, and their performance was measured by comparing improvement between a pre-test and a post-test. We found no difference between participants who worked alone with the application, were instructed by the experimenter while using the application, or who instructed the experimenter on how to solve equations using the application. Further research is needed to examine how and whether analogous sensory-motor interfaces are a useful learning tool, and if so, what circumstances are ideal for sensory-motor interfaces to be used. 


\section{TABLE OF CONTENTS}

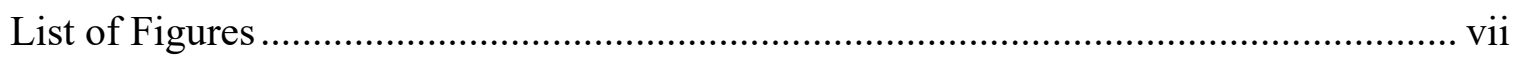

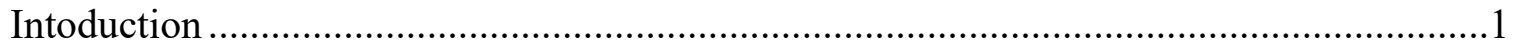

Advancements in Cognitive Science …………………......................................

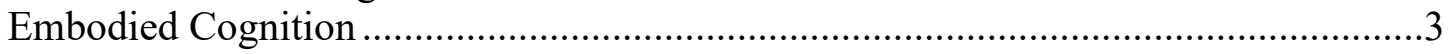

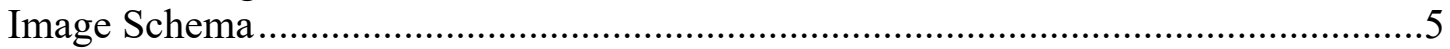

The Mathematical Idea Analysis ..........................................................................

Embodied Cognition in Pedagogy …………………………................................... 10

Full Body Interactive Learning Environments (FUBILES).........................................11

Research on Manipulatives as a Teaching Tool .....................................................15

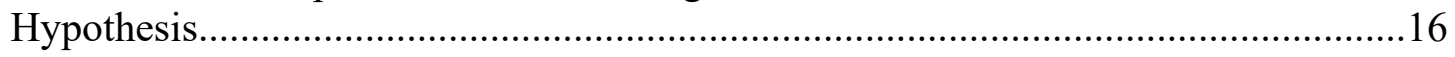

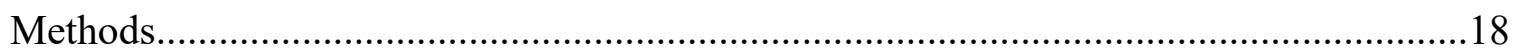

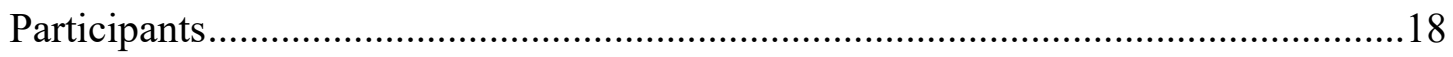

Materials and Procedures ...............................................................................18

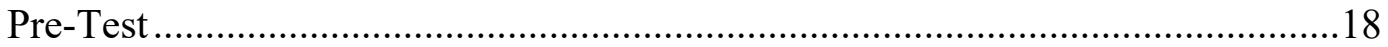

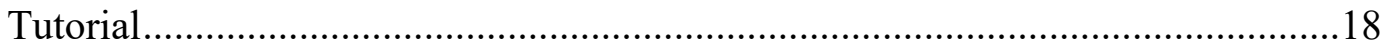

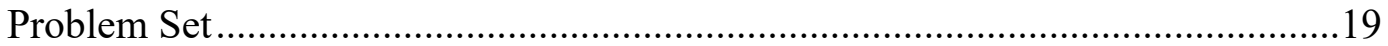

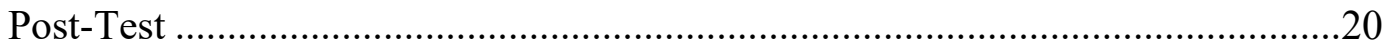

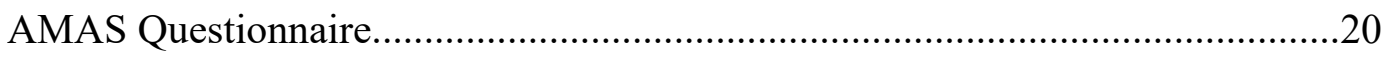

Demographic Questionnaire .........................................................................20

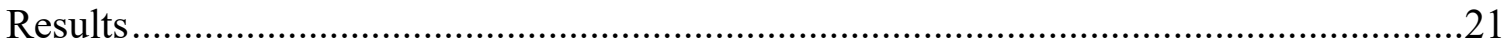

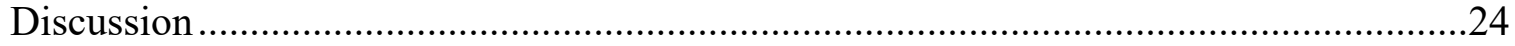

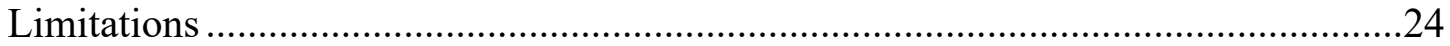

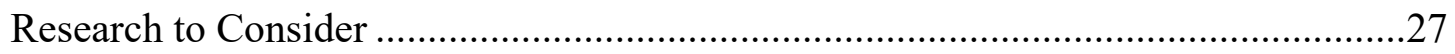

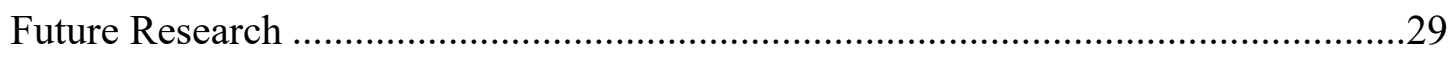

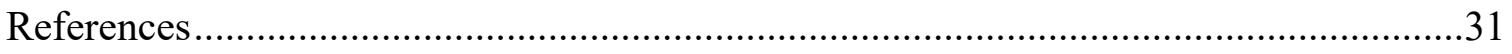

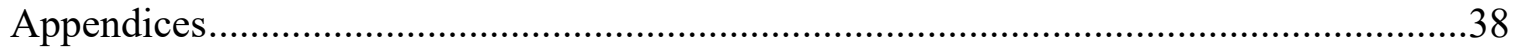

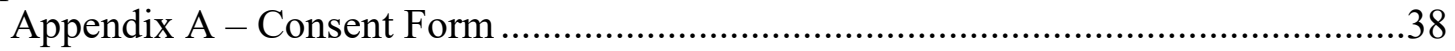

Appendix B - Pre-Test...................................................................................

Appendix C - Problem Set ………………………………………………...41

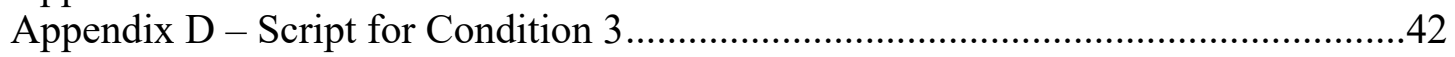

Appendix E - Post-Test ..........................................................................................4

Appendix F - Additional Materials Accompanying AMAS Questionnaire ..................45 
Appendix G - Background Information

Appendix $\mathrm{H}-$ Debrief Form . 


\section{LIST OF FIGURES}

Figure 1. Mean test improvement between the pre-test and the post-test.......................23

Figure 2. Mean rating of participants' anxiety levels after finishing the test portion of the

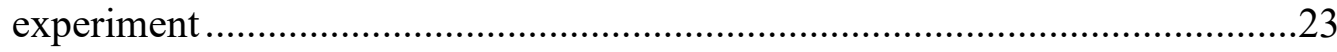




\section{Introduction}

\section{Advancements in Cognitive Science}

Our study examines a new pedagogical approach that draws its methodology from

research on embodied cognition. Embodied cognition is the theory that behaviors and conceptualizations are rooted in physiological and environmental feedback, instead of arising entirely from cognitive computations and algorithms. The field of cognitive science is currently undergoing a paradigm shift from computational theories towards embodied cognitive theories. Pedagogical researchers are interested in applying embodied cognition theories on conceptual learning to classroom settings for K-12 students as well as college students. One approach is called Embodied Full Body Interactive Learning Environments (embodied FUBILEs), which contains several different active-learning approaches, including sensorimotor manipulation as a representation for the concept, group collaboration, and gamification. Students who learn in classroom designs with embodied FUBILEs methods generally perform better on tests compared to students who learn the same concept through standard lecturing or textbooks (Malinverni \& Pares, 2014). Since there are so many components attached to embodied FUBILEs, the underlying reason for why students perform better on tests is not clear. In our study, we isolate one component, sensorimotor manipulation as a representation of the learning material, and measure its effect on student performance. The complexity of FUBILEs leaves room for variation in each design, and some components may be more effective than others, or work better in conjunction.

Scientific advancement requires a set of universally accepted axioms to base new discoveries on, which are called paradigms. In his book, The Structure of Scientific 
Revolutions Vol. II, Kuhn (2012) describes paradigms as empirically tested models for the scientific community to use as a foundation to advance research and knowledge (p. 10). A paradigm is a scaffold for other theories to build on, and if its validity comes into question, all of the research that relies on it becomes suspect as well. For example, virtually all credible neuroscience relies on the paradigm that neuronal information is transferred through interconnected neuronal synapses. Any robust research contradicting this paradigm would cause a major overhaul of all modern neuroscientific research. Major scientific progression occurs through what Kuhn calls a "Scientific Revolution," a gradual shift from older paradigm to a new paradigm (p. 92). The new paradigm is incompatible with most of the field's research, because all research has been built off of the old paradigm. An example of paradigm shifts in psychology is the change from introspection to behaviorism.

Our research focuses on a recent scientific revolution in cognitive science called embodied cognition. Embodied cognition is a recent paradigm shift from the computational view of cognition, which holds a dualistic view of the mind and body. Computational cognitive scientists assume that the brain processes information similarly to a computer, with an input and output system and separate processing stages to internalize information (Shapiro, 2011). The processing stage holds a hub for amodal mental representations of external stimuli (Pfeifer, Bongard, \& Grand, 2007). Researchers were able to advance with computational cognitive science because they focused their work on high-cognition tasks that can be performed through discrete sets of logic or algorithmic calculations. Artificial intelligence (AI) in particular thrived with creating simulations that were able to perform cognitive tasks, like math or chess, but the 
theory failed to explain many cognitive tasks, such as language formation or deciphering incomplete information.

Another paradigm, called connectionism, attempted to accurately explain the cognitive processes where computational cognition failed. Connectionist models eliminated the complexity of programming a set of rules for every single process, but models still relied on mental representations and the brain being the seat of all cognition (for a more detailed explanation, see McClelland and Rumelhart's (1986) research on parallel distributed processing). The next paradigm, embodied cognition, changed the dualistic paradigm that cognitive psychology had rested on for centuries, and expanded cognition beyond the brain.

\section{Embodied Cognition}

Embodied cognition posits that cognitive processes expand beyond the brain to the body (Wilson, 2002). Since the theory's debut, there have been many adaptations of it; however, the premise of the theory remains that cognition is not restricted to the brain (for more details on different adaptations, see Wilson 2002). Studies using animals, AI, and children support theories for embodied cognition by showing how complex behaviors that appear purely cognitive are explainable through physical and environmental cues. For example, the Portia spider adapts its behavior to stalk prey in ways that seem intentional and highly intelligent (Barrett, 2011). The Portia spider engages in deceptive mimicry to fool its prey, takes long detours to avoid prey's attention, and will create distractions to divert its prey. The Portia's behavior is impressively dynamically responsive to the environment and the prey's behavior, especially for an animal with a small brain size, but research on how Portia spiders navigate their environments shows a 
lack of any sort of internal map or intentional strategy. When stalking their prey, Portia spiders do not actually plot their route to reach their target, though their behavior would suggest otherwise. Portia spiders stop and "scan" the area before continuing their route, turning their legs to an angle that gives them a full range of view. Scanning behavior is done on the fly, and Portia spiders simply continue towards horizontal features. If they come to an end of the horizontal feature, they will scan and take a different route. There are no internal representations of a barricade or a map to navigate on, just the simple rule to follow the horizontal feature until it stops.

Embodied cognition has also been tested in developmental psychology, in one case, by emphasizing the body and environment's role in Piaget's A-not-B error. The A-not-B error is a task in which babies are presented with a toy and two boxes (box A and B). The toy is placed under box A, and the baby correctly lifts box A to retrieve the toy. This task is completed several times, followed by a break, and then the toy is placed under box B. Babies under 10 months will generally continue to search under Box A. Piaget explained these findings as a cognitive error called "perseverative error," caused by a lack of schema for object permanence. Piaget's explanation leads one to believe that the error lies entirely in the mental development of the baby. Changes in the body and environment can alter the baby's response to the task. For example, removing the time delay will reduce the baby's likelihood of making a preservation error on the task, indicating Piaget's findings may just be due to a time delay in the stimulus (Thelen, Schöner, Scheier, \& Smith, 2001). Another compelling finding is the change in performance by adding weights to the baby's arms (Smith, 2005). Babies who are given heavy weights are less likely to make an error than babies without weights, indicating 
that the baby's attention is being affected by their sensory feedback. There is a growing number of studies and theories that sensorimotor feedback influences concept formation beyond infancy. These studies contrast with Piagetian beliefs that concept development and sensori-motor information is established through separate systems in children older than infants (Gibbs, 2005; Glenberg \& Gallese, 2011; Wellsby \& Pexman, 2014).

\section{Image Schema}

The previous examples all demonstrate the role that bodies and the environment have on decision making and behaviors, but they fail to explain higher-level cognitive performance as successfully as theories computational cognitive science were able to explain them. In light of this, theories on the role of embodied cognition in abstract concept formation and understanding have become popular. The predominant theory is the Grounded Cognition Theory, which holds that abstract concepts are grounded in image schema, meaning our understanding of abstract concepts are rooted in body schemata (Johnson \& Lakoff, 1980). Our understanding of the world from a pre-lingual age is formed by our sensory-motor experiences. Though we are not able to conceptualize or verbalize our thoughts, we are learning that certain stimuli produce a pleasant or unpleasant response. For example, being in a dark area brings uncertainty and fear, whereas being somewhere well lit brings certainty and ease in navigating our surroundings.

We cannot learn anything about abstract concepts through our five senses. According to the grounded cognition theory, abstract concepts are conceptualized and understood through our early sensory-motor experiences. We use these experiences to later understand concepts we cannot directly perceive. For example, a relationship is often 
described by using spatial or temperature metaphors, i.e. "we are very close," or "he gave me a warm embrace" (Johnson \& Lakoff, 1980). Numbers in mathematics are generally visualized as falling sequentially on a number line, though numbers themselves do not actually exist in any formation (Núñez \& Lakoff, 2000). Children demonstrate linear reasoning as early as second grade, and linear reasoning becomes more prevalent as children get older. Children describe a mental linear plane as their reference for number estimation and number categorization (Laski \& Sielger, 2007; Siegler \& Booth, 2004). Children's tendency to use linear reasoning was positively correlated with their accuracy on tasks, implicating that perceptual thinking (in this case, numbers falling on a grid) is beneficial for math comprehension (Siegler \& Opfer, 2003).

According to Lakoff's theory, conceptual schema networks for sensory-motor experiences overlap with schema networks for abstract concepts. These image-schematic models can be visualized as a set of neural networks for sensory-motor schema overlapping with networks for the corresponding abstract concept. Image schema form by simultaneous neural firings caused by repeated exposure to a series of stimuli around the same timeframe. For example, young children are repeatedly exposed to a variety of containers--cases, jars, rooms, pockets, etc.--which all fall into a schema for containers. The concept for "container" is visualized as having an inside and an outside and being capable of holding something else. The concept for physical containers can then be used as a scaffold to understand different abstract concepts, such as being depressed (stuck in a hole, feeling empty, etc.). 


\section{The Mathematical Idea Analysis}

Math is also understood through metaphor, and our understanding of concepts are influenced by our sensory-motor experiences. The Mathematical Idea Analysis, developed by Núñez and Lakoff (2000), posits that sensory-motor schema are unconsciously integrated with mathematical thinking and influences our mathematical understanding. Our mathematical understanding is shaped by our sensory system, our physical composition, and our interactions with the environment. This contrasts from the classical view of mathematics comprehension resulting from an amodal and highly logical processing system. Humans have a very limited set of innate mathematical skills, meaning most of our mathematical ability is determined by our experiences. Our innate skills do not extend beyond subitizing small numbers and conducting very rudimentary arithmetic.

One innate mathematical ability is subitizing, the ability to distinguish between a small set of objects--usually up to four objects. It is easy to immediately recognize a pattern of two versus three objects, but not so easy to recognize a pattern of seven objects versus eight objects. Several species can subitize, including rhesus monkeys, rats, and crows (Yaman, Kilian, von Fersen, \& Güntürkün, 2012). Prelingual infants can also subitize, indicating that subitizing comes before the ability to conceptualize numbers (Starkey \& Cooper, 1980). Infants also show dishabituation when 1 object is subtracted from 2 objects, or 1 object is added to 1 object, suggesting a primitive understanding of the arithmetic concept of addition and subtraction.

There is ample evidence that our innate mathematical ability is extremely limited; as infants, we have numerosity, subitizing, and we are able to conduct very basic arithmetic. 
Yet, as educated adults, we are able to grasp complex numeric concepts such as Euler's number, e, or pi, and can apply mathematical knowledge to our environment. According to the Mathematical Idea Analysis, we are able to learn higher mathematics through sensory-motor experience, and by understanding the abstract concepts in math through metaphor. While some researchers believe that humans have an innate number line because it is evolutionarily beneficial, there is evidence that the number line is a relatively new invention. There is some research suggesting that number lines may be an inherent concept, and can be found across cultures, including indigenous groups without formal math education (Dehaene, Izard, Spelke, \& Pica, 2008; Dehaene, Piazza, \& Pinel, 2003). On the other hand, written recordings of number lines do not span through recorded history or across all cultures. Ancient civilizations such as Mesopotamia, Ancient Egypt, and China did not use any sort of tools with a number line (Núñez, 2011). Additionally, there is contrasting evidence on cross-cultural research on populations without formal education, and some groups struggle to find endpoints of a number line. The recent development of the number line and the diversity of conceptualizing numbers throughout history indicates no innate imagery for numerics, but rather the development of a metaphor.

Numbers are abstract concepts that can only be symbolized with characters, objects, or pictures. However, using a number line allows us to conceptualize numbers as if they are objects that can be manipulated. Núñez, Edwards, and Matos (1999) identified common metaphors used to understand series of numbers. One common visual for number series is a continuous line with discrete points (whole numbers) falling along the line, when in actuality, numbers do not fall on any sort of line. Numbers and equations 
are also placed on a physical grid, as if manipulable in space. Landy and Goldstone (2007) measured whether students who could accurately recall the order of operations rules would perform correctly when the spacing was changed in an equation. Students who viewed validity equations with counterintuitive spacing (e.g., when variables with an addition sign are closer together than variables with a multiplication sign: $\mathrm{w}+\mathrm{n} * \mathrm{r}+\mathrm{k}=$ $\mathrm{r}+\mathrm{k} * \mathrm{w}+\mathrm{n}$ ) made six times more errors than students who received equations with normal spacing or intuitive spacing. If students were simply using abstract logic to solve the equations, they would have not made mistakes due to spacing. Students also demonstrate a tendency to group symbols that are bound together by rules of order of operations when they write out equations (Landy \& Goldstone, 2007).

Students' gestures and verbal language also indicate unconscious perceptual influence on algebraic thought. Students more fluent in physics demonstrated a verbal problemsolving process of moving variables in equations (Wittmann, Flood, \& Black, 2013). Students who were observed and recorded during a group-quiz were more likely to use motion-based language and gestures when solving a physics equation if they were better at physics. Students who performed more poorly were more likely to use formal, Euclidian language. These findings suggest that students who are better at math tend to think of math in perceptual terms, rather than formal logic equations. Additionally, when students were asked to verbalize their process of solving fractions, their gestures and verbal descriptions involved "cutting," "slicing," "taking something out of a whole," and similar descriptions (Edwards, 2009). Metaphoric gestures and verbal descriptions have also been found in describing Cartesian graphs by using motion and orientation, solving for unknown variables using sweeping over motions to move variables on the other side 
of equal signs, adding and subtracting by pointing and covering up numbers, and using equalizing language to balance equations (Broaders, Cook, Mitchell, \& Goldin-Meadow, 2007; Cook, Mitchell, \& Goldin-Meadow, 2008; Font, Bolite, \& Acevedo, 2010; GoldinMeadow, Cook, \& Mitchell, 2008).

\section{Embodied Cognition in Pedagogy}

Lectures continue to be largely used in US classroom settings, despite growing research criticizing lecture-based teaching and a recent surge of technology designed to teach using non-lecture-based platforms. The National Science Foundation (1996) has cautioned against using lectures, stating that this approach results in negative outlooks on STEM fields of study, insufficient prerequisite knowledge to succeed in a STEM field in college, and an inability to solve real world problems in careers. Arch (1998) surveyed teachers and faculty of K-12 schools, who reported using lectures as their main pedagogical method despite feeling that better teaching methods may exist. Teachers and faculty continue to rely heavily on lecturing because they are unaware of better methods.

Some teachers have attempted to move away from lectures by shifting their focus on ways to implement more active-learning pedagogical approaches in the classroom. Active learning is any teaching approach in which students are actively involved in their own learning, students participate more than listen, students learn information by developing skills through activity rather than by passively receiving information, and emphasis is placed on students examining their own perceptions and attitudes (Keyser, 2000). In sum, active learning is an approach that requires students to complete a task, and think about how they complete the task. In a 1993 national survey, 79\% of elementary school teachers and $62 \%$ of middle school teachers stated they consistently use a form of 
cooperative learning in their classrooms (Springer, Stanne, \& Donovan, 1999). There is currently a growing interest in incorporating the more hands-on, collaborative, and creation-based aspects of the Maker Movement into curriculums, particularly for STEM courses (Martin, 2015). The Maker Movement steers classroom structures away from passive, independent learning to more active-based learning.

Active learning approaches may give students a boost in their performance in classrooms. Freeman, Eddy, McDonough, Smith, Okoroafor, Jordt, and Wenderoth (2014) compared undergraduate student success in active learning versus traditional lecture- STEM courses. Students learning material in a traditional lecture setting were 1.5 times more likely to fail their STEM courses (33.8\% failure rate) than students who learned material with active learning. (21.8\% failure rate). Even though the failure rate is still high for students enrolled in active learning courses, their overall improvement may offer a rough blueprint or indicator for a better learning method. Another study by Yoder and Hochevar (2005) compared standard lecture, autonomous reading, and video activities to active learning approaches in an undergraduate Women's Studies course. Active learning included discussions of materials classwide or among a small group, learning exercises, simulations, demonstrations, and/or completing and discussing measurement scales (e.g., the Objectified Body Consciousness Scale). Material learned through active learning yielded higher mean test scores and a lower variability among students' scores.

\section{Full Body Interaction Learning Environments (FUBILEs)}

Pedagogical researchers have been turning towards research in embodied cognition and abstract concepts for ways to improve classroom performance. One such recent 
research trend using embodied techniques is called Full Body Interaction Learning Environments, or FUBILEs (Malinverni \& Pares, 2014). The goal of FUBILEs is for children to learn abstract concepts by using their body and surrounding physical space as a metaphor for an abstract concept. FUBILEs can be approached from a developmental, embodied, or physiological approach. Each approach has its own structure and methodology, but for the purposes of this study, we will only focus on the embodied approach. The embodied approach is rooted in theories like image-schematic models and the Mathematical Idea Analysis, in which concrete and abstract concepts overlap.

Enyedy, Danish, Delacruz, and Kumar (2012) conducted a study on FUBILEs using learning approaches on Newtonian physics (force, net force, friction, and twodimensional motion) for students ages six to eight. Students acted out physics properties using socio-dramatic play. In one particular session on force, a student played the role of a ball and decided when to speed up and slow down, depending on the forces the other students assigned to her. Another study by Antle, Corness and Bevans (2009) used a physically interactive computer program to teach individuals about sound parameters, which they claimed corresponded to the metaphor "music is movement". Participants were asked to create sound sequences by moving their bodies through space. Physically acting out metaphors to teach numerous other concepts have been tested, including using a dancing-mat to teach spatial-numerical mathematics, using physical balancing to understand the justice system, a motion-based interface to understand geological concepts, playing a team game with water to promote peace and global understanding, and several others (Antle, Corness, \& Bevans, 2013; Fischer, Moeller, Bientzle, Cress, \& Nuerk, 2011; Johnson-Glenberg, Birchfield, Savvides, \& Megowan-Romanowicz, 2011; 
Parés, Carreras, \& Durany, 2005; for a more extensive review, see Malinverni \& Pares, 2014).

When studying FUBILEs, researchers attempt to create a classroom curriculum using embodied techniques and generally conduct research on K-12 students, particularly around ages ten and eleven, when children are believed to start conceptualizing abstract concepts in Piagetian-based theories (Malinverni \& Pares, 2014), though the age and underlying mechanisms of abstract concept conceptualization in Piaget's theories are generally not accepted among embodied cognition researchers (Pexman, 2017). An interface or simulation is provided to enhance students' sensory-motor interaction with the concept. All FUBILEs projects involve students using hands-on physical or sensorymotor activity in order to learn an abstract concept. The embodied approach to FUBILEs particularly aims to use physical and spatial experiences to create a metaphor for an abstract concept. FUBILEs' success is generally measured by participants' performance on a post-test after undergoing a new curriculum. Success is evaluated by whether students significantly improve on the post-test. Studies provide no breakdown of which/how individual components of the multifaceted FUBILEs methodology lead to post-test improvement (Malinverni \& Pares, 2014).

Embodied cognition FUBILEs designs have many components distinguishing them from the standard lectures most often used in schools. One example is a study by Johnson-Glenberg, Birchfield, Savvides, and Megowan-Romanowicz (2011), who tested a multi-sensory interface to teach geological concepts. To support the Grounded Cognition theory, students physically interacted with an object or interface in order to gain sensory-motor experience about a concept, for example, physically moving sliders to 
adjust mass, stiffness, and damping. The sensory-motor activity must be representative of a metaphor of the abstract concept. The activity is generally meant to be enjoyable and exploratory, as if an educational game. Students manipulate the environment themselves to learn about the concept, or they follow along with a teacher. Often, the concepts are learned through group activities, with teams working together to discover a goal. Students do not use standard school materials to learn activities; they are often provided high-tech interfaces with which to work. This embodied study alone contains several other components in its design: physical movement, metaphor, self-directed learning, group activities, and gamification. By only measuring post-test improvement, there is no way to decipher which components of this complex design is beneficial for students.

The shift from lecture-based theory to embodied FUBILEs and the binary approach to analyzing its success makes it difficult to tell which aspect of the design is contributing to student improvement in learning. Educational studies show that students improve in settings that involve concrete examples of abstract concepts (Goldstone \& Son, 2005; McNeil \& Fyfe, 2012; Rutten, van Joolingen, \& van der Veen, 2012): students benefit from self-directed learning (Abdullah, 2001; Garrison, 1997; Knowles, 1975) students benefit from working in groups (Johnson, Johnson, \& Smith, 1998; Johnson, Johnson \& Stanne, 2000; Lou, Abrami, \& d'Apollonia, 2001; Puma, 1993; Springer \& Stanne, 1999;), and students benefit from gamification (an extensive review can be found by Hamari, Koivisto, \& Sarsa, 2014). Embodied cognition FUBILEs emphasize the importance of using sensory-motor experiences to generate conceptual understanding, but there are several other components used in a FUBILEs research design that are also known to enhance student learning. Post-test improvement may be due to a variety of 
other factors other than physical engagement. Physical engagement may not even be necessary or helpful in teaching abstract concepts.

It is difficult to say which factor in FUBILEs is really causing improvement, particularly, whether the "embodied portion" component of FUBILEs is making an impact on students' learning. Measuring the usefulness of each component of FUBILEs is important so we can better understand how each factor contributes to students' performance.

\section{Research on Manipulatives as a Teaching Tool}

Several researchers have pushed against using physical manipulatives as a method of learning (Ball, 1992; Ma, 1999; McNeil \& Jarvin, 2007; Zacharia \& Olympiou, 2011). For example, a study by Zacharia and Olympiou (2011) compared physical manipulatives for learning, virtual online tutorials, and standard lecture approaches. They found no difference in improvement among students. Contrarily, several researchers advocate for manipulatives in the classroom (Cramer, Post, \& del Mas, 2002; Gürbüz, 2010; Witzel, Mercer, \& Miller, 2003). For example, Witzel, Mercer and Miller found that using concrete and pictorial manipulatives when teaching math improved scores for at-risk students.

A meta-analysis by Carbonneau, Marley, and Selig (2013) covers studies that show improvements from using manipulatives and studies that show no difference between manipulatives and standard learning approaches. They attribute the differences in outcomes to varying factors such as teacher involvement, age of students, and type of manipulatives used. They divided the different moderators into instructional guidance, concept being taught, development stage, level of perceptual stimulus, and amount of 
instructional time. These factors all affect how much the student improves while using manipulatives. Carbonneau and colleagues conclude that manipulatives aid learning depending on factors of these moderators, but they cannot conclude that manipulatives alone assist in learning.

\section{Hypothesis}

In this study, we aimed to measure whether physically emulating an abstract concept improves performance. Specifically, we aimed to measure whether using physical motion similar to how an abstract concept is unconsciously understood actually facilitates learning, and whether isolating this portion of FUBILEs as a learning technique contributes independently of other learning techniques in FUBILEs, such as discussion or group activities. By isolating this specific technique, we aimed to understand how abstract concepts are organized and understood, and understand how we can change pedagogical approaches to be more aligned with how people naturally learn abstract concepts. There are several different ways to implement embodied cognition theory into pedagogy (gestures, sociodramatic play, using motion-based language to solve an equation, etc.), but some methods may be more beneficial than others. Our study compared whether physically moving algebraic symbols is better than using motionbased language when solving algebraic equations.

In our study, we gave participants an application designed for tablets that required them to solve algebraic equations by physically moving numbers and symbols around on the screen. Participants either physically moved around the symbols themselves, physically moved the symbols through instruction, or instructed someone else to move around the symbols using the motion-based language required to interact with the 
application. This divides the tablet's application interaction into three approaches:

physical interaction and working alone, physical interaction and being instructed, and no physical interaction but instructing someone else.

We predicted that acting as an instructor would yield more post-test improvement than physically interacting with the tablet, and solving equations alone on the tablet would yield more post-test improvement than being instructed and following along on the tablet. We believed this is true because physical activity itself is not beneficial, but instructing while using motion-based language is beneficial. Our findings will help researchers understand which portion of physical metaphor is important in learning an abstract concept.

Because math anxiety is a major contributor to students' performance (Ashcraft, 2002; Ashcraft \& Krause, 2007; Meece, Wigfield, \& Eccles, 1990; Ramirez, Gunderson, Levine, \& Beilock, 2013; Wu, Amin, Barth, Malcarne, \& Menon, 2012), we also measured general anxiety as a possible covariate for post-test performance, as well as anxiety during the experiment to see whether different tasks between conditions cause higher anxiety among participants. Our findings will help to see if the level of anxiety alters participants' preferences for and improvement from each of the instructional approaches. Additionally, participants were asked about their anxiety during the experiment. This was to measure any differences in anxiety levels that could have been caused by the different approaches in each condition, which could influence participants' performance. 


\section{Methods}

\section{Participants}

A total of 130 undergraduate students with a mean age of 19.4 (86 females, 54 males) participated in return for partial course credit for their Introduction to Psychology courses. Thirty-seven participants were in condition 1 (control), 36 participants were in condition 2 (instructing but no physical movement), and 37 participants were in condition 3 (physical movement and following along with instructions). We omitted 10 participants' data for not following directions properly or for not finishing before time ran out. This project was approved as exempt by the Institutional Review Board (Appendix A).

\section{Materials and Procedures}

The experiment was a between-subjects design. One participant was run in each experimental session. Participants completed a pre-test, practice tutorial, post-test, the abbreviated math anxiety survey (AMAS), and a questionnaire measuring education level, demographics, and anxiety during the test.

Pre-Test. Participants had up to 10 minutes to fill out a 10-item pre-test measuring their initial performance on algebraic concepts (Appendix B). Pre- and post-test questions aimed to measure conceptual comprehension on order of operations (PEDMAS), the associative property, the distributive property, and the commutative property.

Tutorial. After the pre-test, participants completed a tutorial on the iPad application Algebra Touch, version 1.0 from Regular Berry software created by Sean Berry (Regularberry.com, 2016). From Here to There allows users to physically manipulate algebraic equations using the touch screen. Users can solve for an unknown variable 
through direct manipulation of the equation by using gestures such as swiping, dragging a number, and tapping symbols. Participants were given as much time as they needed to complete the tutorial, and alerted the experimenter when they were finished. Participants were permitted to ask questions if they were unable to solve a portion of the practice tutorial themselves or if they were unsure how to use the application.

Problem Set. After completing the tutorial, participants completed a six-item problem set using From Here to There (Appendix C). The items were conceptually similar to the equations on the pre-test and post-test (PEDMAS, associative property, distributive property, and commutative property).

The three conditions differed in how participants approached the problem set:

- Condition 1 (Working Individually, the control condition): Participants completed the problem set with no experimenter interaction. Participants physically manipulated symbols themselves.

- Condition 2 (Participant as Instructor): Participants told the experimenter how to solve equations while the experimenter followed their instructions on the iPad. If the participant had to restart the problem three times, then the experimenter guided them on how to solve the equation.

- Condition 3 (Participant being Instructed): The roles of the participant and experimenter were switched from condition 2. Experimenters used a script to instruct the participants on how to solve the problems in the problem set using motion-based language specific to From Here to There (Appendix D). The participant only contributed by following along on the iPad. 
Post-Test. After completing the problem sets, all participants took a post-test (Appendix E). Equations on the post-test were structurally the same as the pre-test but contained different numbers, so that the steps to solve the equation were the same. Participants had up to 10 minutes to complete the post-test.

AMAS Questionnaire. After completing the post-test, participants took the AMAS, which is a survey measuring general math anxiety (Appendix F). The AMAS contains nine questions about the level of anxiety participants have in different math-related situations (taking a test, listening to a lecture, etc.). All questions are ranked using a 5point Likert scale. A score of 5 is considered extreme anxiety. The AMAS has high internal consistency $(\alpha=.90)$, and test-retest reliability $(r=.85)$ (Hopko, Mahadevan, Bare, \& Hunt, 2003), which made it an ideal measurement for general math anxiety.

Demographic Questionnaire. In the final portion of the experiment, participants completed a questionnaire about their level of education, anxiety while undergoing the experiment, and their demographics (Appendix G). The demographics portion was optional. The experiment was complete after participants were done with the questionnaire. Participants were given a debrief form after completion (Appendix $\mathrm{H}$ ). 


\section{Results}

All analyses were run on IBM SPSS Statistics version 20. To measure test performance between conditions, we ran a one-way analysis of variance (ANOVA) using the difference in number of correct answers from the pre-test and the post-test. To measure whether general anxiety affected students' scores in each condition, we ran an analysis of covariance (ANCOVA) using the mean scores from each participant's responses on the AMAS survey. We also ran a one-way ANOVA on the AMAS results. To measure whether any tasks between the conditions caused more anxiety, we ran a oneway ANOVA on the average score of participants' response to anxiety felt during the experiment between conditions.

Participants who instructed the experimenter (condition 2) had the same level of improvement $(M=1.11, S D=1.76)$ as participants who solved equations alone (condition 1) $(M=1.05, S D=1.99)$, and the same level of improvement as participants who were instructed by the experimenter (condition 3$)(M=.63, S D=1.68)$. The differences between conditions were not large enough to be significant $F(2,111)=.776$, $p=.46$. We also used a 7-point Likert scale asking students to report their anxiety specific to the experiment ( 7 being the highest level of anxiety). We compared experiment-specific anxiety to measure whether any of the methods used in each condition caused higher anxiety for participants, for example, whether having to act as an instructor caused more anxiety than being instructed. Participants who instructed had the same level of anxiety $(M=3.69, S D=1.37)$ as participants who were instructed $(M=$ $3.18, S D=1.48)$ and participants who worked alone $(M=3.03, S D=1.82)$. The 
differences between conditions were not large enough to be significant $F(2,111)=1.69$, $p=.19$.

Participants' mean score on the AMAS was calculated to measure general math anxiety. The AMAS questionnaire revealed the same pattern among participants as the question about experiment specific anxiety, with participants who acted as instructor reporting the same level of math anxiety on the AMAS $(M=2.85, S D=.57)$ as participants who were instructed $(M=2.50, S D=.71)$ and participants who worked alone $(M=2.63, S D=.72)$. The differences were not large enough to be significant $F(2,111)$ $=1.244, p=.09$. Lastly, we measured whether general anxiety reported on the AMAS was a covariate for participants' performance. There were no significant differences between conditions $F(2,110)=1.419, p=.246$. The mean difference in the number of correct answers between the pre-test and post-test are found in Figure 1, and participants' reported anxiety levels between conditions are found in Figure 2. 


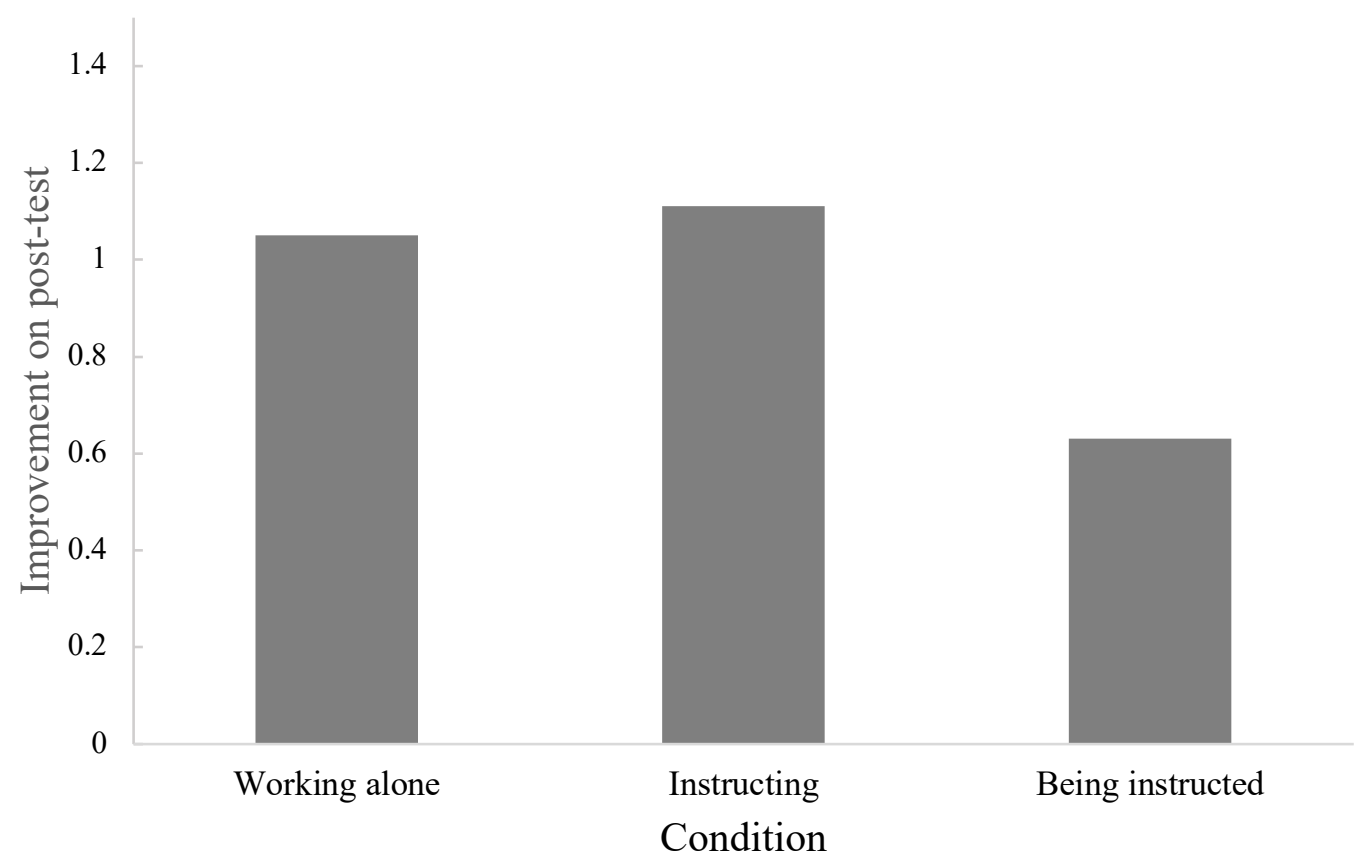

Figure 1. Mean test improvement between the pre-test and the post-test.

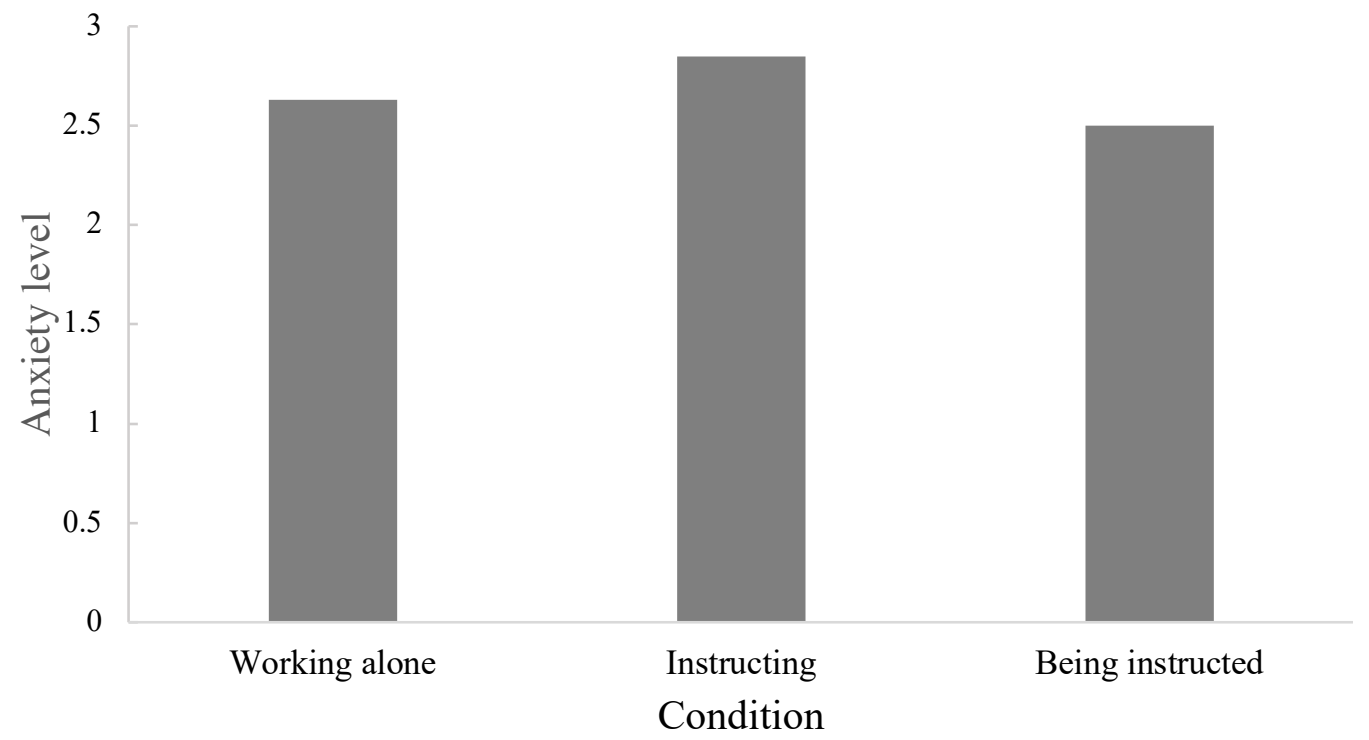

Figure 2. Mean rating of participants' anxiety levels after finishing the test portion of the experiment. 


\section{Discussion}

We wanted to test whether the popular pedagogical approach of physical manipulation really helps students learn abstract concepts, in our case, simple algebraic concepts. Participants who instructed but did not physically interact with the interface did not have significantly higher post-test improvement as students who interacted directly with the interface. We also measured how experiment-specific anxiety and general math anxiety affects performance. Participants who instructed reported had the same level of anxiety about their performance as participants who were instructed reported the lowest anxiety about their performance. We measured whether there were any main effects on general math anxiety in each condition. Participants acting as instructor reported the same level of general anxiety as participants being instructed. Lastly, we analyzed general math anxiety as a possible covariate for overall performance on the test. There was no main effect on performance based on anxiety levels, suggesting that participants with high math anxiety were not necessarily affected by doing math in this experiment. The mean level of anxiety in each condition was moderate. Moderate levels of arousal and anxiety boost performance on difficult cognitive tasks, whereas high and low levels of arousal and anxiety hinder performance; this is known as the Yerkes-Dodson law (Yerkes \& Dodson, 1908). Despite this, participants did not show much improvement between tasks.

\section{Limitations}

One limitation of this experiment is its unrealistic expectations of the participants' ability to learn algebraic concepts from a short tutorial in under an hour on a type of interface they had likely never encountered, especially considering the generally poor 
performance on the pre-test. Participants were expected to complete a task that would be done over several days in a classroom setting, and then consolidate enough of that information and improve on a post-test. The time constraint on the learning and practice portion of the experiment may have hindered participants' ability to actually learn and consolidate the content at all. A more ideal approach is for participants to learn how to use the application before implementing the problem set, and to have a longer problem set and more test questions before implementing a post-test.

Even though participants were supposed to focus on a different approach to learning algebra, they were required to also learn how to use the application simultaneously. The exercise may have been more confusing because participants were trying to learn how to use the application more than they were trying to learn how to do the equations. In an ideal setting, students would already be fluent with the application before learning a new concept, so they could focus their energy on learning algebraic concepts instead of using a confusing application while trying to learn a concept. Focusing on the task of explicitly trying to remember the motions to complete an action on From Here to There (instead of being practiced enough to use the application implicitly) along with trying to learn a new mathematical concept may have hindered learning.

Another potential limitation is that participants may not feel motivated to learn a concept they will not need after the study is complete. Participants were granted credit despite their post-test performance as long as they completed the experiment. There was no motivation for participants to learn, as it was an ungraded, confidential, mandatory study. Motivation is an essential factor to learn material, especially in our design in which participants completed the tutorial and problem set alone (Mega, Ronconi, \& De Beni, 
2014; Zimmerman, 2008). Having no incentive to learn the material itself separates this experiment from a classroom setting, in which students have a range of motivators, such as grades, advancement, self-esteem, and desire to know more about a topic.

Our study lacked ecological validity, whether the environment is at home, in a classroom, or in extracurricular learning settings. Our experiment's main restriction was the amount of time we had to teach participants about the application and teach them a new concept, in enough time for them to show improvement. Ideally, students would be given as much time as they needed to learn the application before engaging in the problem set portion of the experiment. They would be given additional time to go over several more problems in their respective conditions instead of the small number of problem sets they had to go through. Lastly, in an ideal situation, participants would have time to do other things before taking the post-test.

The aforementioned meta-analysis by Carbonneau, Marley, and Selig (2013) discusses moderators for manipulatives in math education. Moderators for a greater chance of significant improvement include the following: math topic, when studies used arithmetic and algebra; instructor interference, with more instructional guidance; developmental stage, with students who had reached the concrete operational stage of learning; length of time, with long lengths of time; the type of assessment, with standardized testing; number of participants, with enough participants to meet the statistical assumption; and experiment design, with within-subjects designs over quasiexperimental designs and between-subjects experimental designs. Our study successfully met the criteria for math topic, developmental stage, and number of participants, but failed to meet criteria for length of time, type of assessment, and experiment design. 
Instructional interference varied between conditions. Failing to allow enough time, use standardized tools, and a between-subjects design may have been the shortcomings in which we were unable to reach significant differences.

\section{Research to Consider}

While this study aimed to demonstrate that physical movement is not necessary when using embodied learning approaches, it is important to note that several studies support the theory that physical motion helps students learn abstract concepts, particularly when students use gesturing while problem solving. The previously mentioned study by Wittman and colleagues (2014) demonstrates that students who spontaneously use gesturing when they are trying to solve equations perform better on tests. They observed eighth grade students who were discussing a physics test in pairs. Students who used motion-based language (e.g., carry the $x$ over to the other side of the equation) to solve equations performed better than students who were using formal logic (e.g., subtract $\mathrm{x}$ on both sides) to solve equations. Students who use gesturing on their own while learning a concept also perform better on tests than students who do not use any gesturing (Pine, Lufkin, \& Messer, 2004). Gestures can be taught and boost performance. Students who were given a lecture that includes both verbal and gesture descriptions performed better on tests and used their own gestures when problem solving, whereas students taught through standard lecturing performed worse and used less gesturing (Wagner-Cook \& Goldin-Meadow, 2006). Students who are told to gesture while solving problems also perform better, suggesting that there is something about movement and gesturing itself helps with learning. These findings are contrary to our hypothesis because they suggest that movement, particularly gesturing, leads to better performance. 
There is some evidence of neural activity in motor regions of the brain during abstract concept solving. One pilot study conducted by Henz, Oldenberg, and Schollhorn (2016) measured restricted versus free movement during mathematical learning, and took EEG measurements before, during, and after the mathematical practice. The EEG results showed activity in visuo-motor regions when students are allowed to freely move while discussing difficult math problems as well as improvement on math tests, which the authors assign as bodily movement playing a role in their understanding. Students with unrestricted movement also performed better on complex mathematical problems, which the authors attribute to being able to combine movement with abstract learning. While it is possible that visuo-motor regions were active simply because the students were moving, the underlying neurological and physiological mechanisms accompanied with abstract concept problem solving should still be considered.

When using manipulatives, instructional guidance may be necessary for student success. A review by Marley and Carbonneau (2014) details the importance of instructional guidance while using manipulatives in classrooms. Designs with instructional guidance are more effective than allowing students to have more selfdirected guidance when they are working with manipulatives (Fyfe, McNeil, Son, \& Goldstone, 2014; Nurmi \& Jaakkola, 2006). As mentioned, Carbonneau, Marley, and Selig (2013) used a meta-analysis to compare manipulatives with high and low instructional guidance, and found that students perform better with manipulatives paired with high instructional guidance. Our method may have lacked enough complexity in its instructional design for students to show any improvement between the pre-test and the post-test. Considering how carefully controlled and unique instructional designs need to 
be when using manipulatives, it begs the question of their efficacy over other designs with high instructional guidance. Instructional guidance may be important for all learning environments, not just when students are using manipulatives (Alfieri, Brooks, \& Aldrich, 2011).

\section{Future Research}

We suggest to researchers who are interested in pursuing the effectiveness of physical movement on abstract learning draw their research from normal classroom settings. Participants could be given a physical task that is easier to comprehend than the iPad application used in this study to ensure that they will not struggle with it in addition to understanding the abstract concept. Additionally, a setting in which participants are allowed more time to learn the concept is necessary to ensure that they have enough of a chance to learn. Students are generally given more than half an hour to learn material before taking a test on it. Lastly, a classroom setting would be ideal because students are more motivated to learn than in an experimental setting.

Lakoff and Johnson's theory (2008) on embodied cognition having an effect on abstract concepts has been empirically tested using behavioral measures, but little experimentation has been done in the neuroscience realm. Some research, such as Henz and colleague's study (2016), suggests there is an overlap between motor areas and higher cognitive areas when students are freely allowed to gesture while solving math problems, but there is little research on the neuroscience of image schemas. Further neurological investigation using both standard and embodied approaches to learning would help solidify a neurological difference in different methods of learning, and 
experimenters could compare these neurological underpinnings with behavioral outcomes. 


\section{References}

Abdullah, M. H. (2001). Self-Directed Learning. ERIC Digest.

Alfieri, L., Brooks, P. J., Aldrich, N. J., \& Tenenbaum, H. R. (2011). Does discoverybased instruction enhance learning? Journal of Educational Psychology, 103(1), $1-81$.

Antle, A. N., Corness, G., \& Bevans, A. (2013). Balancing justice: comparing whole body and controller-based interaction for an abstract domain. International Journal of Arts and Technology, 6(4), 388-409.

Antle, A. N., Corness, G., \& Droumeva, M. (2009). What the body knows: Exploring the benefits of embodied metaphors in hybrid physical digital environments. Interacting with Computers, 21(1), 66-75.

Arch, S. (1998). How to teach science. Science, 279(5358), 1869-1869.

Ashcraft, M. H. (2002). Math anxiety: Personal, educational, and cognitive consequences. Current Directions in Psychological Science, 11(5), 181-185.

Ashcraft, M. H., \& Krause, J. A. (2007). Working memory, math performance, and math anxiety. Psychonomic Bulletin \& Review, 14(2), 243-248.

Ball, D. L. (1992). Magical Hopes: Manipulatives and the Reform of Math Education. American Educator: The Professional Journal of the American Federation of Teachers, 16(2).

Barrett, L. (2011). Beyond the brain: How body and environment shape animal and human minds. Princeton University Press.

Broaders, S. C., Cook, S. W., Mitchell, Z., \& Goldin-Meadow, S. (2007). Making children gesture brings out implicit knowledge and leads to learning. Journal of Experimental Psychology: General, 136(4), 539.

Carbonneau, K. J., Marley, S. C., \& Selig, J. P. (2013). A meta-analysis of the efficacy of teaching mathematics with concrete manipulatives. Journal of Educational Psychology, 105(2), 380.

Cook, S. W., Mitchell, Z., \& Goldin-Meadow, S. (2008). Gesturing makes learning last. Cognition, 106(2), 1047-1058.

Cramer, K. A., Post, T. R., \& delMas, R. C. (2002). Initial fraction learning by fourth- 
and fifth-grade students: A comparison of the effects of using commercial curricula with the effects of using the rational number project curriculum. Journal for Research in Mathematics Education, 33(2), 111-144.

Dehaene, S., Piazza, M., Pinel, P., \& Cohen, L. (2003). Three parietal circuits for number processing. Cognitive neuropsychology, 20(3-6), 487-506.

Dehaene, S., Izard, V., Spelke, E., \& Pica, P. (2008). Log or linear? Distinct intuitions of the number scale in Western and Amazonian indigene cultures. Science, $320(5880), 1217-1220$.

Edwards, L. D. (2009). Gestures and conceptual integration in mathematical talk. Educational Studies in Mathematics, 70(2), 127-141.

Enyedy, N., Danish, J. A., Delacruz, G., \& Kumar, M. (2012). Learning physics through play in an augmented reality environment. International Journal of ComputerSupported Collaborative Learning, 7(3), 347-378.

Fischer, U., Moeller, K., Bientzle, M., Cress, U., \& Nuerk, H. C. (2011). Sensori-motor spatial training of number magnitude representation. Psychonomic Bulletin \& Review, 18(1), 177-183.

Font, V., Bolite, J., \& Acevedo, J. (2010). Metaphors in mathematics classrooms: analyzing the dynamic process of teaching and learning of graph functions. Educational studies in Mathematics, 75(2), 131-152.

Freeman, S., Eddy, S. L., McDonough, M., Smith, M. K., Okoroafor, N., Jordt, H., \& Wenderoth, M. P. (2014). Active learning increases student performance in science, engineering, and mathematics. Proceedings of the National Academy of Sciences, 111(23), 8410-8415.

Fyfe, E. R., McNeil, N. M., Son, J. Y., \& Goldstone, R. L. (2014). Concreteness fading in mathematics and science instruction: A systematic review. Educational Psychology Review, 26(1), 9-25.

Gibbs Jr, R. W. (2005). Embodiment and cognitive science. Cambridge University Press.

Glenberg, A. M., \& Gallese, V. (2012). Action-based language: A theory of language acquisition, comprehension, and production. Cortex, 48(7), 905-922.

Goldin-Meadow, S., Cook, S. W., \& Mitchell, Z. A. (2009). Gesturing gives children new ideas about math. Psychological Science, 20(3), 267-272.

Goldstone, R. L., \& Sakamoto, Y. (2003). The transfer of abstract principles governing 
complex adaptive systems. Cognitive Psychology, 46(4), 414-466.

Goldstone, R. L., \& Son, J. Y. (2005). The transfer of scientific principles using concrete and idealized simulations. The Journal of the Learning Sciences, 14(1), 69-110.

Gürbüz, R. (2010). The effect of activity-based instruction on conceptual development of seventh grade students in probability. International Journal of Mathematical Education in Science and Technology, 41(6), 743-767.

Hamari, J., Koivisto, J., \& Sarsa, H. (2014, January). Does gamification work?--a literature review of empirical studies on gamification. In 2014 47th Hawaii International Conference on System Sciences (pp. 3025-3034). IEEE.

Henz, D., Oldenburg, R., \& Schöllhorn, W. (2015, February). Does bodily movement enhance mathematical problem solving? Behavioral and neurophysiological evidence. In CERME 9-Ninth Congress of the European Society for Research in Mathematics Education (pp. 412-418).

Johnson, D. W., Johnson, R. T., \& Smith, K. A. (1998). Cooperative learning returns to college what evidence is there that it works? Change: the magazine of higher learning, 30(4), 26-35.

Johnson, D. W., Johnson, R. T., \& Stanne, M. B. (2000). Cooperative learning methods: A meta-analysis. Retrieved August 10, 2013, from http://www.cooperation.org/pages/cl_methods.html

Johnson, M., \& Lakoff, G. (1980). Metaphors we live by. University of Chicago.

Johnson-Glenberg, M. C., Birchfield, D., Savvides, P., \& Megowan-Romanowicz, C. (2011).

Semi-virtual embodied learning-real world stem assessment. In Serious Educational Game Assessment (pp. 241-257). SensePublishers.

Kaminski, J. A., Sloutsky, V. M., \& Heckler, A. F. (2006, July). Do children need concrete instantiations to learn an abstract concept. In Proceedings of the 28th annual conference of the Cognitive Science Society (pp. 411-416).

Keyser, M. W. (2000). Active learning and cooperative learning: understanding the difference and using both styles effectively. Research strategies, 17(1), 35-44.

Knowles, M. S. (1975). Self-directed learning: A guide for teachers and learners. New York: Associated Press. 
Koedinger, K. R., \& Nathan, M. J. (2004). The real story behind story problems: Effects of representations on quantitative reasoning. The Journal of the Learning Sciences, 13(2), 129-164.

Kuhn, T. S. (2012). The structure of scientific revolutions. University of Chicago press.

Lakoff, G., \& Núñez, R. E. (2000). Where mathematics comes from: How the embodied mind brings mathematics into being. Basic books.

Landy, D., \& Goldstone, R. L. (2007). Formal notations are diagrams: Evidence from a production task. Memory \& Cognition, 35(8), 2033-2040.

Landy, D., \& Goldstone, R. L. (2007). How abstract is symbolic thought? Journal of Experimental Psychology: Learning, Memory, and Cognition, 33(4), 720.

Laski, E. V., \& Siegler, R. S. (2007). Is 27 a big number? Correlational and causal connections among numerical categorization, number line estimation, and numerical magnitude comparison. Child Development, 78(6), 1723-1743.

Lou, Y., Abrami, P. C., \& d'Apollonia, S. (2001). Small group and individual learning with technology: A meta-analysis. Review of educational research,71(3), 449521.

Ma, L. (1999). Knowing and teaching elementary mathematics: Teachers understanding of fundamental mathematics in China and the United States. Mahwah, NJ: Lawrence Erlbaum Associates.

Malinverni, L., \& Pares, N. (2014). Learning of Abstract Concepts through Full-Body Interaction: A Systematic Review. Educational Technology \& Society, 17(4), $100-116$.

Marley, S. C., \& Carbonneau, K. J. (2014). Theoretical perspectives and empirical evidence relevant to classroom instruction with manipulatives. Educational Psychology Review, 26(1), 1-7.

Martin, L. (2015). The promise of the maker movement for education. Journal of PreCollege Engineering Education Research (J-PEER), 5(1), 4.

McClelland, J. L., Rumelhart, D. E., \& PDP Research Group. (1986). Parallel distributed processing. Explorations in the microstructure of cognition, 2. 12-21.

McNeil, N. M., \& Fyfe, E. R. (2012). “Concreteness fading” promotes transfer of mathematical knowledge. Learning and Instruction, 22(6), 440-448.

McNeil, N.M., \& Jarvin, L. (2007). When theories don't add up: Disentangling the 
manipulatives debate. Theory into Practice, 46(4), 309-316.

Meece, J. L., Wigfield, A., \& Eccles, J. S. (1990). Predictors of math anxiety and its influence on young adolescents' course enrollment intentions and performance in mathematics. Journal of Educational Psychology, 82(1), 60.

Mega, C., Ronconi, L., \& De Beni, R. (2014). What makes a good student? How emotions, self-regulated learning, and motivation contribute to academic achievement. Journal of Educational Psychology, 106(1), 121-131.

National Science Foundation (1996). Shaping the future: New expectations for undergraduate education in science, mathematics, engineering, and technology.

Washington, DC: Report by the Advisory Committee to the National Science Foundation Directorate for Education and Human Resources

Núñez, R. E. (2011). No innate number line in the human brain. Journal of CrossCultural Psychology, 42(4), 651-668.

Núñez, R. E., Edwards, L. D., \& Matos, J. F. (1999). Embodied cognition as grounding for situatedness and context in mathematics education. Educational Studies in Mathematics, 39(1-3), 45-65.

Nurmi, S., \& Jaakkola, T. (2006). Effectiveness of learning objects in various instructional settings. Learning, Media and Technology, 31(3), 233-247.

Parés, N., Carreras, A., \& Durany, J. (2005). Generating meaning through interaction in a refreshing interactive water installation for children. In Proceedings of Interaction Design and Children (pp. 218-223).

Pfeifer, R., Bongard, J., \& Grand, S. (2007). How the body shapes the way we think: a new view of intelligence. MIT press.

Pine, K. J., Lufkin, N., \& Messer, D. (2004). More gestures than answers: children learning about balance. Developmental Psychology, 40(6), 1059.

Puma, M. J. (1993). Prospects: The Congressionally Mandated Study of Educational Growth and Opportunity. The Interim Report.

Ramirez, G., Gunderson, E. A., Levine, S. C., \& Beilock, S. L. (2013). Math anxiety, working memory, and math achievement in early elementary school. Journal of Cognition and Development, 14(2), 187-202.

Berry, S. (2016). Regular Berry Software. From Here to There (Version 1.0) 
[Computer Software]. Retrieved from http://www.regularberry.com/

Rutten, N., van Joolingen, W. R., \& van der Veen, J. T. (2012). The learning effects of computer simulations in science education. Computers \& Education, 58(1), 136153.

Shapiro, L. A. (2011). Embodied cognition. London: Routledge.

Siegler, R. S., \& Booth, J. L. (2004). Development of numerical estimation in young children. Child development, 75(2), 428-444.

Siegler, R. S., \& Opfer, J. E. (2003). The development of numerical estimation: Evidence for multiple representations of numerical quantity. Psychological Science, 14(3), 237-250.

Smith, L. B. (2005). Cognition as a dynamic system: Principles from embodiment. Developmental Review, 25(3), 278-298.

Springer, L., Stanne, M. E., \& Donovan, S. S. (1999). Effects of small-group learning on undergraduates in science, mathematics, engineering, and technology: A metaanalysis. Review of Educational Research, 69(1), 21-51.

Starkey, P., \& Cooper, R. G. (1980). Perception of numbers by human infants. Science, 210(4473), 1033-1035.

Thelen, E., Schöner, G., Scheier, C., \& Smith, L. B. (2001). The dynamics of embodiment: A field theory of infant perseverative reaching. Behavioral and Brain Sciences, 24(01), 1-34.

Uttal, D. H., Scudder, K. V., \& DeLoache, J. S. (1997). Manipulatives as symbols: A new perspective on the use of concrete objects to teach mathematics. Journal of Applied Developmental Psychology, 18(1), 37-54.

Wellsby, M., \& Pexman, P. M. (2014). Developing embodied cognition: insights from children's concepts and language processing. Frontiers in Psychology, 5, 506. Wilson, M. (2002). Six views of embodied cognition. Psychonomic Bulletin \& Review, 9(4), 625-636.

Wittmann, M. C., Flood, V. J., \& Black, K. E. (2013). Algebraic manipulation as motion within a landscape. Educational Studies in Mathematics, 82(2), 169-181.

Witzel, B. S., Mercer, C. D., \& Miller, M. D. (2003). Teaching algebra to students with learning difficulties: An investigation of an explicit instruction model. Learning Disabilities Research \& Practice, 18(2), 121-131. 
Wu, S., Amin, H., Barth, M., Malcarne, V., \& Menon, V. (2012). Math anxiety in second and third graders and its relation to mathematics achievement. Frontiers in Psychology, 3, 162.

Yaman, S., Kilian, A., von Fersen, L., \& Güntürkün, O. (2012). Evidence for a numerosity category that is based on abstract qualities of "few" vs. "many" in the bottlenose dolphin (Tursiops truncatus). Frontiers in Psychology, 3.-115

Yerkes, R. M., \& Dodson, J. D. (1908). The relation of strength of stimulus to rapidity of habit-formation. Journal of comparative neurology and psychology, 18(5), 459-482.

Yoder, J. D., \& Hochevar, C. M. (2005). Encouraging active learning can improve students' performance on examinations. Teaching of Psychology,32(2), 91-95.

Zacharia, Z. C., \& Olympiou, G. (2011). Physical versus virtual manipulative experimentation in physics learning. Learning and Instruction, 21(3), 317-331.

Zimmerman, B. J. (2008). Investigating self-regulation and motivation: Historical background, methodological developments, and future prospects. American Educational Research Journal, 45(1), 166-183. 


\section{Appendix A: Consent Form}

\section{Agreement to Participate in Research}

Title of Study: Learning Simple Math

You have been asked to participate in a research study investigating learning techniques and math comprehension. The Primary Investigator of this study is Cassandra Durkee, a current MA student at San Jose State University.

In this experiment, you will take a short pre-test asking you to solve some algebraic formulas. You will then watch a short video lecture on how to do an algebra problem. Then, you will complete a problem set. Following this activity, you will complete a short post-test and a questionnaire. All of your answers will be recorded on paper.

If you are prone to math anxiety, there is the possibility that you will feel some anxiety during this study. Your identity will remain anonymous and your performance will not contribute towards your grade.

You will receive 1 credit for your participation in this study. Additionally, you will be contributing to the advancement of scientific knowledge and the potential improvement of learning techniques in educational institutions.

Although the results of this study may be published, no information that could identify you will be included. Your responses and behaviors are entirely anonymous and cannot be traced back to you in any way. To assure your anonymity, you will be assigned a number.

Questions about this research may be addressed to Cassandra M. Durkee, (319) 3309706, cmdurkee@gmail.com. Complaints about the research may be presented to Ronald Rogers, Ph.D, Department Chair, Psychology Department, (408) 924-5652. Questions about a research subjects' rights, or research-related injury may be presented to Pamela Stacks, Ph.D., Associate Vice President, Graduate Studies and Research, at (408) 9242427.

No service of any kind, to which you are otherwise entitled, will be lost or jeopardized if you choose not to participate in the study.

Your consent is being given voluntarily. In order to receive credit, you must complete the entire study. You are free to leave the study at any point, but you will not receive credit for your participation, and you will be required to complete an alternative assignment assigned by your instructor.

At the time that you sign this consent form, you will receive a copy of it for your records, signed and dated by the investigator. 
- The signature of a subject on this document indicates agreement to participate in the study.

- The signature of a researcher on this document indicates agreement to include the above named subject in the research and attestation that the subject has been fully informed of his or her rights. 


\section{Appendix B: Pre-Test}

\section{Pre-Test}

Please solve for $x$ to the best of your ability and show all of your work. You have 10 minutes to complete this test. Report back to the experimenter when you are finished.

1. $\frac{3 \times 9+3 x}{3}=6$

2. $\frac{8 \times 29+-8 x}{8}=12$

3. $\frac{14 \times 10+-21 x}{7}=4 x$

4. $6+\frac{10 \times 18+-50 x}{5}=25 x+7$

5. $2 \times(5 x+3)=\frac{8 \times 12 x+64}{8 x+9}$

6. 8 times 16 plus 8 times an unknown number is divided by 8 , which equals 7 . What is the unknown number?

7. 14 times 24 plus 7 times an unknown number is divided by 2 , which equals 5 . What is the unknown number?

8. 15 times 27 is subtracted by 45 times an unknown number, then divided by 3 , which equals 12 . What is the unknown number?

9. 30 companies bring 5 wines to a wine tasting event, and 6 companies bring an unknown number of ports. The drinks are divided among 12 different booths, depending on taste. There were 15 wines and ports in each booth. How many ports did each of the 6 companies bring?

10. 12 children volunteer to plant trees. Each child plants 3 trees. Six of the children plant some additional trees. The trees are planted in 4 different parks. Each park ends up having 24 new trees. How many additional trees did each of the 6 children plant? 


\section{Appendix C: Problem Set}

\section{Problem Set}
1. $\frac{12 \times 16+48 x}{12}=20$
2. $\frac{15 \times 36+30 x}{45}=54$
3. $\frac{13 x+9 \times 39}{26}=10$
4. $\frac{8 x+7 \times 2}{4}=61$
5. $\frac{7 x+15 \times 21 x}{14}=80$
6. $\frac{12 \times 8+24 x}{6}=17 x$ 


\section{Appendix D: Script for Condition 3}

Tell the participant:

- They are going to follow along on the iPad as you work through a problem set with them

- As you tell them what to do, they need to complete it on the iPad.

- If they are unable to use the iPad, they will need to go through the lecture again.

You will be telling the participant how to solve problems (like an instructor). Make sure the participant follows along with what you are saying on the iPad.

If the participant does not remember how to do a certain portion, you can remind/work through the problem with them, however make sure they are not just sitting there saying they don't know how to solve the problem. Give them leeway on the first and second problem in the problem set, but after that, if they claim to not know how to use the iPad more than 3 times, have them go through the lecture again.

\section{How to complete problem set}

$$
1 . \frac{12 \times 6+48 \mathrm{x}}{12}=20
$$

Drag open (pinch two fingers over, then pull apart) the 48 and type in $12 * 4$.

Drag the 12 in $12 * 4$ over to overlap with the 12 in $12 * 6$, so you get a distribution.

Hold your finger down and drag it across the 12 in the numerator and denominator to cancel out.

Carry over the 16 to the other side of the equation.

Tap the subtraction sign between 20 and 16 to get 4 .

Carry over the 4 in $4^{*} \mathrm{x}$ to the other side of the equation.

Swipe your finger across the 4 's in the numerator and denominator to reduce the fraction.

$\frac{46 \times 36+30 x}{15}=54$

Drag open the 30 and type in $15 * 2$.

Drag open the 45 and type in $15 * 3$.

Drag the 15 in $15 * 2$ to overlap with the 15 in $15 * 3$, so you get a distribution.

Swipe out the 15 's in the numerator and denominator.

Tap the multiplication sign in $3 * 36$.

Carry over the 108 to the other side of the equation.

Tap the subtraction sign to combine 54 and 108.

Carry over the 2 to the other side of the equation.

Swipe the -54 and the 2 .

Swipe out the 2's. 
$\frac{13}{26 x+9 \times 52}=10$

This one is a little different, because the numerator and denominator are switched.

Drag open the 52 and type in $13 * 4$.

Drag open the 26 and type in $13 * 2$.

Carry over the 13 in $13 * 4$ to the 13 in $13 * 2$.

Swipe out the 13 in the numerator and denominator.

Tap the multiplication sign in $9 * 4$ to get 36 .

Drag over the entire bottom equation by selecting the plus sign, and dragging to the other side of the equation to get $10 *(2 * x+36)$.

Distribute by tapping the multiplication sign. When a slider appears below the equation, slide it left to right.

Move the 360 back to the other side of the equation, and subtract it from 1.

Move the 20 over to the other side of the equation.

$\frac{16 \mathrm{x}-7 \times 8}{8}=61$

Drag open the 16 and type in $8 * 2$.

Drag the 8 in $7 * 8$ to over to overlap with the other 8 .

Swipe out the 8 in the numerator and the denominator.

Move the 7 over to the other side of the equation.

Tap the addition sign to combine 61 and 7.

Move the 2 over to the other side of the equation.

Swipe the 68 and the 2 .

Swipe the 2's in the numerator and denominator.

$\frac{24 x-6 \times 8}{6}=20$

Drag open the 24 and select $6 * 4$.

Select the 6 in $6^{*} 8$ and drag it over the 6 in $6^{*} 4$.

Swipe out the 6's in the numerator and denominator.

Drag over the 8 to the other side of the equation.

Tap the addition sign to combine 20 and 8 .

Drag over the 4 to the other side of the equation.

Swipe the 28 and 4.

Swipe out the 4's. 


\section{Appendix E: Post-Test}

Please solve for $x$ to the best of your ability and show all of your work. You have 10 minutes to complete this test. Report back to the experimenter when you are finished.

1. $\frac{7 \times 31+7 x}{7}=41$

2. $\frac{4 \times 8+4 x}{2}=28$

3. $\frac{15 x \times 10}{25 \times 5}=10 x$

4. $\frac{4 \times 15+-12 x}{5 \times 5}=8 x+11$

5. $43 x+7=\frac{7 \times 18 x+56}{7}$

6. 11 times 22 plus 11 times an unknown number is divided by 11 . The answer is 31 . What is the unknown number?

7. 16 times 30 plus 8 times an unknown number is divided by 4 . The answer is 22 . What is the unknown number?

8. 12 times 23 plus 36 times an unknown number, then divided by 3 . The answer is 46 . What is the unknown number?

9. A worker spends 7 hours painting houses, plus an undocumented amount of overtime painting houses. Five other workers spend 21 hours painting. The overall work is divided among 14 houses. On average, each house received 12 hours of work. How much undocumented time did the worker spend painting?

10. A catering company caters the first 2 entrees for a set price of $\$ 300$ each, then charges a fee of $\$ 150$ for each additional entree. The catering company is catering to 50 people. After purchasing the additional entrees, the total price for each person is $\$ 30$ each. How many additional entrees were purchased? 


\section{Appendix F: Additional Materials Accompanying AMAS Questionnaire}

Please answer the following questions.

Using the following scale, rate how much you enjoyed the training method you were given:

$1=$ extremely disliked $\quad 2$ = somewhat disliked $\quad 3=$ neutral $\quad 4=$ somewhat enjoyed $\quad 5=$ extremely enjoyed

Using the following scale, rate how much you felt you learned during the training session:

$1=$ much less than usual $\quad 2=$ somewhat less than usual $\quad 3=$ no change

$4=$ somewhat more than usual $\quad 5=$ a lot more than usual

Thank you for your participation! 


\section{Appendix G: Background Information}

Select the following courses that you have passed with at least a grade of C-. High School Algebra/Pre-Calculus College Algebra/Pre-Calculus High School Calculus College Calculus Finite Math Calculus II or higher other:

When did you take your last mathematics class?

Currently taking Last semester 2 semesters ago 3 semesters ago 4 semesters ago 5 or more semesters ago

Current year in college

\begin{tabular}{|c|}
\hline reshman \\
\hline
\end{tabular}

Gender Male Female Other Decline to State

Age:

Describe your race or ethnic group. Multi-racial descriptions are okay.

On a scale of 1 to 7 , how anxiety producing did you find this overall experience?

Not at all Extremely

$\begin{array}{lllllll}1 & 2 & 3 & 4 & 5 & 6 & 7\end{array}$




\section{Appendix H: Debrief Form}

Thank you for your participation in this experiment. Cognitive psychologists are interested in how people learn mathematical concepts. This study is investigating some of the different approaches to learning algebraic formulas. You were placed in one of three different conditions. The conditions differed by learning style. The pre-test was to measure your initial understanding of factoring, and the post-test was to measure your improvement after learning about factoring. The questionnaire was to measure your general math anxiety. We are hoping that this research will contribute to future algebraic education techniques.

If you are interested in the outcome of this study, please give the experimenter your email. You will receive a summary of the findings when the study is complete. If you have further questions, please contact the Primary Investigator Cassandra Durkee at cmdurkee@gmail.com.

\section{THANKS AGAIN FOR YOUR PARTICIPATION!}

